\title{
Sistema progresivo penitenciario en Colombia: tratamiento y resocialización *
}

\author{
Luz Mireya Mendieta Pineda* \\ Blanca Melania Molina Carrión \\ Omar Huertas Díaz
}

Recibido: 20 de marzo de 2020 • Aprobado: 10 de mayo de 2020

\begin{abstract}
Artículo de investigación desarrollado en cooperación entre el Grupo de Investigación Derechos humanos y Medio ambiente, reconocido y clasificado en Minciencias 2018, de la Universidad Pedagógica y Tecnológica de Colombia (UPTC); el Grupo de Investigación Red Internacional de Política Criminal Sistémica Extrema Ratio UN, reconocido y clasificado en A1 Minciencias 2018, de la Universidad Nacional de Colombia; la Maestría en Derecho Procesal Penal, Universidad Autónoma de Santo Domingo (UASD) y el "Grupo de Investigación en Derechos Humanos y Víctimas en escenario de Postconflicto", reconocido y clasificado en C Colciencias 2018, Unidad Central del Valle del Cauca (uceva).

Citar como: Mendieta Pineda, L. M., Molina Carrión, B. M. y Huertas Díaz, O. (2020). Sistema progresivo penitenciario en Colombia: tratamiento y resocialización. Revista IUSTA, 53, 15-44. DoI: https://doi.org/10.15332/25005286.6270
\end{abstract}

*. Docente investigadora, asociada de la Facultad de Derecho y Ciencias Sociales de la Universidad Pedagógica y Tecnológica de Colombia. Abogada, especialista en instituciones jurídico-políticas. Magíster en Derecho Procesal por la Universidad Libre. Doctora en Derecho Penitenciario por la Universidad Libre. Correo electrónico: luz.mendieta@uptc.edu.co. orcid: org/0000-0003-0371-5012.

-.- Doctora en Derecho por la Universidad Iberoamericana (Unibe), República Dominicana, especialidad en Derechos Humanos y Derecho Internacional Humanitario por el Instituto Superior para la Defensa Insude (en curso). Magíster en Derecho Procesal Penal por la Universidad Autónoma de Santo Domingo (UASD) (en curso). Investigadora en estancia 2019 en el Grupo de Investigación Red Internacional de Política Criminal Sistémica Extrema Ratio UN, reconocido y clasificado en A1 Minciencias 2018 de la Universidad Nacional de Colombia. Correo electrónico: molinacarrion22@gmail.com. oRciD: 0000-0002-5290-5974.

-.-. Doctor en Derecho. Profesor e investigador senior de la Universidad Nacional de Colombia. Doctor en Ciencias de la Educación por la Universidad Simón Bolívar. Magíster en Derecho Penal por la Universidad Libre. Magíster en Derechos Humanos, Estado de Derecho y Democracia por la Universidad de Alcalá, España. Magíster en Educación por la Universidad Pedagógica Nacional. Par evaluador Ministerio de Educación Nacional y Minciencias. Correo electrónico: ohuertasd@unal.edu.co. oRCID: 0000-0002-8012-2387. 


\title{
Resumen
}

El objetivo del presente estudio es explorar el sistema progresivo en Colombia teniendo en cuenta lo contemplado en los artículos 142, 143 y 144 de la Ley 65 de 1993. En este contexto, se analiza si el sistema progresivo introducido en la legislación penal desde 1936 ha tenido eficacia, o si este debe ser replanteado. La metodología de investigación es documental y pretende, a través de la consulta doctrinaria, jurisprudencial, normatividad e informes del INPEC, recoger datos sobre el tema que sustentan la investigación para un análisis de aproximación al objeto de estudio y concluir sobre su ineficacia. Entre los hallazgos se destaca su fracaso.

Palabras clave: prisión, sistema progresivo, tratamiento, resocialización.

\section{The Progressive Penitentiary System in Colombia: Treatment and Resocialization}

\begin{abstract}
The objective of this study is to explore the progressive penitentiary system in Colombia, taking into account the stipulations of articles 142, 143, and 144 of Law 65 of 1993. In view of this context, this article examines whether the progressive system, introduced into criminal legislation on 1936, has been effective, or whether it should be reconsidered. The research methodology is documentary and aims, by means of consulting the doctrines, jurisprudence, norms, and reports of the INPEC, to collect information relative to this topic which underpins the research in order to make an approximation analysis to the subject matter and conclude on its ineffectiveness. Among the findings, it failure stands out.
\end{abstract}

Keywords: prisons, progressive system, treatment, re-socialization.

\section{Sistema PRISIONAL PROgRESSIVO NA ColÔMBIA: TRATAMENTO E RESSOCIALIZAÇÃO}

\section{Resumo}

O objetivo deste estudo é explorar o sistema progressivo na Colômbia levando em consideração o disposto nos artigos 142, 143 e 144 da Lei 65 de 1993. Nesse contexto, analisa-se se o sistema progressivo introduzido na legislação penal a partir 
de 1936 tem sido eficaz ou se deve ser repensado. A metodologia da pesquisa é documental e visa, por meio dos relatórios doutrinários, jurisprudenciais, normativos e dos relatórios do Instituto Nacional Penitenciário e Carcerário (Inpec), coletar dados sobre o tema que subsidiem a pesquisa para uma análise de aproximação do objeto de estudo e concluir sobre sua ineficácia. Entre os achados do estudo, destaca-se o fracasso desse sistema.

Palavras-chave: prisão, sistema progressivo, tratamento, ressocialização.

\section{Introducción}

El objetivo del trabajo es determinar la eficacia del sistema progresivo y del tratamiento penitenciario para entender si se cumple con el fin de la pena, la resocialización; lo anterior a partir de una perspectiva histórica y una revisión documental. De esta manera, para entender el por qué en el régimen penitenciario se habla de sistema progresivo penitenciario establecido en el art 12 de la Ley 65 de 1993, se hace necesario recordar los antecedentes de la pena de prisión, ya que los sistemas penitenciarios, que fueron varios, se originaron con fundamento en el fin de esta.

Adicionalmente, es importante revisar el sistema progresivo en Colombia, sus dinámicas y situaciones; esto permite entender el marco normativo que existe alrededor de este y las dinámicas que se intentan generar dentro de los penales respondiendo a los fines y procedimientos del sistema. Todo lo anterior, nos lleva a una reflexión que parte de mirar más allá del sistema progresivo como norma, observando las dinámicas reales dentro de los centros penitenciarios y la insuficiencia en el cumplimiento de derechos universales, situaciones que obstaculizan el fin último de la pena privativa de la libertad.

\section{Pena de prisión}

\section{Antecedentes de la pena de prisión}

En la Antigüedad se daba el encierro de las personas hasta tanto no fueran juzgadas, mas no para cumplir una condena, luego eran "cárceles de custodia”, cuyo objetivo era mantenerlos separados de la sociedad (López, 2012, pp. 402-403). Mientras en la Edad Media y en la primera mitad de la Edad Moderna se tenía la "prisión del 
Estado", en la que se recluían los enemigos del poder "real o señorial" y se presentaba bajo dos formas: como "cárcel custodia" y la persona esperaba la muerte o como "detención temporal o perpetua" a la opción del perdón real o señorial (López, 2012, p. 407). De la cárcel se decía que el contacto de unos con otros y los malos ejemplos son más contagiosos que una enfermedad epidémica, hace "perversos a los que no lo eran", convirtiéndose las cárceles en escuelas de "iniquidad" y de hombres malos y perniciosos (De Lardizabal, 1782, p. 213); también se presentaba la forzada ociosidad (pp. 213-214).

A finales del siglo xviII, con la desaparición del sistema feudal, el surgimiento de las grandes ciudades, la aparición del humanismo en la ejecución de la pena y las ideas de la Ilustración, surge la necesidad de cambiar las penas existentes por otras ajustadas a la "nueva delincuencia menor", según lo manifiesta Téllez Aguilera, al ser referenciado por Rodríguez (2013, p. 50). Antecedentes de lo que se conoce hoy en día como pena de prisión son varios: uno lo encontramos en el derecho canónico en la Edad Media (específicamente, en los monasterios), en donde se aplicaba a los clericós que hubieran incurrido en pena eclesiástica, a los herejes y delincuentes juzgados por la jurisdicción canónica. La finalidad de la pena privativa de la libertad era reconciliar al pecador con la divinidad (De Pont, 1982). Como pena en sí misma aparece solo con las denominadas casas de corrección, que es considerado también como antecedente de la privación de la libertad (Fleming y Viñals, 2014). Era común encontrar para esa época en una sola institución una variedad de propósitos, ejemplo de ello era la casa Pforzheim, que era orfanato, instituto de ciegos, sordos y mudos, manicomio y colonia penal. Igual situación pasaba en el Instituto de Ludwigsburg, que en 1780 de los 238 reclusos, solo 148 eran delincuentes, el resto eran huérfanos, pobres o dementes (Rusche y Kirchheimer,1984).

Sergio García Ramírez, al estudiar la obra de John Howard, refiere en su estudio introductorio que tras la cárcel preventiva llagaría la "verdadera" prisión: la punitiva, la penitenciaría, lugar de pena, penitencia, pensada, formulada, construida, administrada y consumada para "escarmentar los yerros". La prisión se miró inicialmente como un alivio para relevar la pena de muerte: a más prisión menos suplicio. Se considera que la prisión solucionó las dificultades que se presentaban con la pena y especialmente relevó la pena de muerte (Howard, 2004). Sin embargo, se aplicó desprovista de las mínimas condiciones de respeto a la dignidad humana, ausencia de condiciones sanitarias, hacinamiento y trato degradantes (Muñoz Conde, 2010, p. 508). 
A finales del siglo xviII, la prisión era considerada "un lugar terrorífico y cruel, donde imperaba el hacinamiento, los castigos corporales, la escasa alimentación, los trabajos forzados, enfermedades, humedad y falta de luz. Su única finalidad era separar al condenado de la sociedad" (Fernández, 2005, p. 13); muchos llegaron sanos, pero con el paso de los días su aspecto cambia, se ven demacrados, agotados, lánguidos y "expiran tendidos en el suelo de horrendas celdas" (Howard, 2004, p. 171).

La pena de prisión se fue dando bajo unos parámetros, como fueron la ausencia de condiciones sanitarias, hacinamiento, trato degradante, que ayudaron a las luchas de las reformas penitenciarias, dirigidas a la humanización de la pena y a la búsqueda del respeto de la dignidad humana (Fleming y Viñals, 2014). Se incentivó que de las cárceles desapareciera la suciedad y el hambre, y que "la compasión y la humanidad debían penetrar las puertas de hierro” (Becaria, 2015, p. 71).

La prisión, en la Modernidad, aparece como pena protagónica, buscando la igualdad frente a la punición (Tocora, 2013), la proporcionalidad entre el delito y la pena (Becaria, 2015, p. 70), ser aplicada a delitos no muy graves (p. 72) y en contraposición de las penas infamantes que se venían ejecutando con la mayor barbarie y violación de todos los derechos de la persona como ser humano. Así también lo da conocer Foucault (2002) al narrar cómo eran consideradas las penas físicas. He aquí la jerarquía de los castigos que prescribía: "la muerte, el tormento con reserva de pruebas, las galeras por un tiempo determinado, el látigo, la retractación pública, el destierro" (p. 72). Y considera, además, que la prisión es "natural”, como es natural en nuestra sociedad el uso del tiempo para medir los cambios (p. 212).

Becaria (2015), al estudiar la figura de la prisión, dijo que "es una pena que por necesidad debe, a diferencia de las demás, preceder a la declaración del delito, pero este carácter distintivo suyo no le quita el otro esencial, esto es, que solo la ley determine los casos en que el hombre es digno de esta pena" (p. 62). Si bien es cierto que se tiene como novedosa, su funcionamiento va ligado a la misma sociedad (Foucault, 1976). La prisión es considerada una institución revolucionaria, porque sustituyó en algunos casos la pena de muerte, penas corporales como la tortura y penas infamantes (Muñoz Conde, 2010, p. 508). Sin embargo, un siglo después ya se conocían todos sus inconvenientes; es peligrosa cuando no es útil, y no se ve por qué remplazarla (Foucault, 2002).

Con la expedición de legislaciones penales y con fundamento en la ideología liberal, aparece la pena de prisión como sanción para obtener en el futuro la corrección 
del sentenciado (Sandoval, 1998) y asegurar la recalificación del individuo como sujeto de derecho. El punto de aplicación de la pena es el cuerpo y el alma; luego se parte del postulado de que "todo delito tiene su curación en la influencia física y moral" a través de instrumentos utilizados como formas de coerción, esquemas de coacción aplicados y repetidos, mediante ejercicios que arrancan de los horarios, empleos de tiempo, movimientos obligatorios, actividades, meditación, trabajo en común pero en silencio, respeto y aplicación de buenas costumbres (Foucault, 2002).

A esta nueva forma de pena denominada prisión, le siguió la construcción de cárceles en todo el mundo, las que buscan el mismo fin como, 1) la protección social, 2) la prevención de futuros delitos, 3) la retribución del daño causado y 4) la resocialización del delincuente (Hernández, 2008). Vista la privación de la libertad como el vehículo para adelantar la legitimación científica de la cual se recubre la sanción criminal, observada por sociólogos y psicólogos que les permite la realización de toda clase de experimentos como ratas humanas de lumpen proletariado (Rojas, 1977). El objetivo es separar al delincuente del mundo exterior, dando lugar a que la privación sea aflictiva por despojar al individuo de su derecho a disponer de su persona al privarle de la libertad. Así, la pena de prisión fue evolucionando y paralelamente fue dando paso a la apertura de una serie de sistemas penitenciarios que buscaban que la misma cumpliera un fin (Molina, 2016).

\section{Sistemas penitenciarios}

Según López Melero, los libros de Bentham, Beccaría y Howard sirvieron de base para la reforma penitenciaria en toda Europa en el siglo xix (p. 427) con fundamento en las denuncias que hicieron del "estado de deshumanización" del sistema penitenciario y carcelario (Leganés, 2013, p. 13), paralelamente a la aparición de movimientos que luchaban por la humanización de la ejecución penal (Quintero y Molina, 2013).

Para justificar el fin de la pena de prisión, se fueron dando una serie de sistemas tanto en Norteamérica como en Europa, algunos de ellos con una corta vida jurídica por los efectos negativos que generó en el recluso y otros, como el sistema progresivo, se ha quedado en las legislaciones penitenciarias por casi dos siglos, acomodado a las condiciones actuales.

A partir del siglo xviII, los procesos de ejecución de la pena de prisión se organizaban de acuerdo con unos determinados procesos que dan lugar a la configuración 
de distintos sistemas penitenciarios, entre los que se resaltan - y que serán objeto de estudio- el sistema pensilvánico o filadélfico, el sistema auburniano, el sistema progresivo y el sistema de individualización científica.

\section{Sistema de Filadelfia}

Conocido como sistema pensilvánico, filadélfico o celular. Su fundador fue William Penn y la Philadelphia Society for Alleviating the Miseries of Public Prisions (Neuman, 1971). Se implantó en Filadelfia en el siglo xviı, en la Easter Penitentiary de Filadelfia (Fleming, 2014, p. 477) y se atribuye a una secta de "cuáqueros", un grupo religioso que pretendía suprimir los vicios. La ejecución de la pena se fundamentaba en el aislamiento celular del interno, quien debía permanecer aislado de día y de noche en una celda con una orientación penitencial de meditación y oración, sin oportunidad de visitas (p. 44). Su fundamento era la no violencia y pregonaba evitar los vicios de las prisiones inglesas (López, 2015). La única lectura era el libro de la Biblia, así se pretendía introducir principios humanos y religiosos en el tratamiento de las personas y era considerado adecuado para la rehabilitación, lograr el recogimiento y arrepentimiento (Deym, 2011). La pena de muerte se reservó a los homicidas, a los incendiarios y reos de traición, mientras que para los demás delitos se dictó la privación de la libertad, azotes y trabajos públicos (Neuman, 1971).

Con el tiempo, se les permitió el trabajo en la misma celda, pero no era productivo ni educativo. Este sistema fue un fracaso cuya consecuencia se vio en los problemas mentales conocidos como psicosis carcelaria. Describía Juanatey Dorado que destruía la salud mental del recluso como consecuencia del aislamiento total (Leganés, 2013, p. 16).

De América del Norte pasó a varios países europeos y nórdicos, como fueron: Inglaterra, en 1835; Bélgica, en 1838; Francia, en 1842; Dinamarca, en 1846; Holanda, en 1851; Rusia, en 1852; Suecia, en 1840; Noruega, en 1851, donde llegó a consolidarse pero fue rechazado en el Congreso Penitenciario Internacional de Praga (Leganés, 2013, pp. 17-18).

Hoy en día, este sistema desapareció, es rechazado por las consecuencias negativas que genera en el ser humano. Aunque excepcionalmente se admite el aislamiento, pero no para buscar el fin de la pena, sino como una medida preventiva y que busca proteger "la salud, la seguridad interna, la disciplina y hasta la propia integridad física y mental cuando el propio recluso solicita su aplicación” (Sentencia C-394/95). 
En Colombia, en el art. 126 de la Ley 65 de 1993 recoge la figura del aislamiento y los casos en que es procedente aislar al privado de la libertad. En análisis a esta figura, la Corte Constitucional ha referido "se prevé el aislamiento en celda hasta por sesenta días, caso en el cual la norma establece que tendrá derecho a dos horas diarias de sol y no podrá recibir visitas, y será controlado ese aislamiento por el médico del establecimiento" (Sentencia C-394/95).

En otras ocasiones, se ha rechazado porque atenta contra la dignidad humana y pone en riesgo la integridad física del privado de la libertad por las condiciones a las que se somete, como lo pudo constatar la Corte y por ello afirmó que:

En muchos de los centros de reclusión, los presos sometidos a régimen de aislamiento no disfrutan ni siquiera de una hora de sol; permanecen todo el día en la celda de confinamiento. En algunos centros de reclusión, los presos en aislamiento nunca abandonan su celda puesto que éstas son dotadas con un pequeño espacio encerrado que recibe sol en el curso del día. Varios de los lugares de aislamiento visitados no están suficientemente protegidos del ambiente, particularmente de la lluvia y su acumulación. (Sentencia T-684/05)

Este sistema de aislamiento es rechazado en los principios básicos para el tratamiento de los reclusos adoptados y proclamados por la Asamblea General de las Naciones Unidas en su Resolución 45/111, de 14 de diciembre de 1990 en su numeral 7: "Se tratará de abolir o restringir el uso del aislamiento en celda de castigo como sanción disciplinaria y se alentará su abolición o restricción”, porque termina convirtiéndose en una pena cruel, inhumana y denigrante para el privado de la libertad y violando sus derechos fundamentales.

\section{Sistema auburniano}

Este sistema se impuso en la cárcel de Auburn, del Estado de Nueva York en el año de 1821, siendo director Elam Lynds, quien lo implementó con las siguientes características: 1) aislamiento celular nocturno; 2) trabajo en común durante el día; 3) sujeción a la regla del silencio absoluto (Fleming, 2014). A través de estas tres condiciones, se pretendía evitar la contaminación criminal, muy común en los centros carcelarios. El trabajo desarrollado en los talleres era en silencio absoluto, su incumplimiento acarreaba castigos corporales inhumanos como "el gato de las nueve colas" y el "chicote" (Neuman, 1971). 
Se prefería este sistema, que desde el punto de vista económico era más rentable, educaba al preso en una actividad útil y en los hábitos de la docilidad productiva (Anitua, 2004). El objetivo del sistema el "silencio" entre los privados de la libertad (De Pont, 1975) para evitar las fugas, motines y "contactos diferenciales". Este sistema fue criticado por el deterioro de la personalidad y la desocialización (López, 2015). Así fue recogido prácticamente por la mayoría de las cárceles y estas se transformaron de nuevo en empresas económicamente rentables (Rusche, 1984).

Este sistema se implantó en "la cárcel de Sing-Sing abierta en el año de 1828", posteriormente en la cárcel de Baltimore y así se expandió a casi todos los estados de Estados Unidos, pasando luego a Europa en Cerdeña, Suiza y en algunas cárceles de Alemania e Inglaterra. Sin embargo, este sistema fue de preferencia en los Estados Unidos (De Pont, 1975a). Las ventajas que presentaba era que permitía organizar el trabajo y la instrucción, y prevenía el planeamiento de fechorías tanto dentro como fuera de la prisión (De Pont, 1975b).

\section{Sistema progresivo}

Los sistemas progresivos tienen su origen en Europa durante la primera mitad del siglo xix y se sostuvo durante los siglos xx y xxi. Posee una orientación hacia una finalidad correctiva y en sus inicios fueron ejemplo cuatro sistemas: el español de Montesinos, el inglés de Maconochie, el alemán de Obermayer, y el irlandés de Walter Crofton. Estos sistemas, a diferencia del norteamericano (filadelfico y auburniano), representan un avance porque elimina el aislamiento celular, el silencio y busca llevar progresivamente al penado "a la vida ordinaria y a la libertad", dando un gran valor al buen comportamiento del recluso (Leganés, 2013 p. 21). Lo más representativo es mientras el condenado está en privación de la libertad, se divide el tiempo fases o periodos, llevándolo gradualmente a alcanzar la libertad antes de cumplir la totalidad de la pena; para tal efecto, es indispensable la buena conducta y el trabajo del recluso. Tales periodos estaban divididos en tres: 1) prueba en el aislamiento diurno y nocturno con la obligatoriedad del trabajo, 2) trabajo en común con el resto de los compañeros durante en día y el aislamiento en la noche, y 3) la libertad condicional (López, 2012, p. 422).

El más conocido, el sistema español de Montesinos, fue introducido por el coronel Manuel Montesinos y Molina, quien inicialmente fue nombrado pagador del presidio de la plaza de Valencia, precursor del tratamiento humanitario. 
En septiembre de 1834 fue comandante del presidio de Valencia, año en el que se expide el Real Decreto del 14 de abril, en el que se aprobó la Ordenanza General de los presidios (López, 2012, p. 423. Una vez nombrado en la dirección del establecimiento, en 1835 puso en práctica el primer sistema progresivo (Fernández, 2013); ganándose la confianza y afecto de los presos. Su método se dirigió a los hombres que habían delinquido, tenía una única finalidad, la corrección. Intentó la disciplina inalterable, vigilada y prevenida, y consideró el trabajo como el medio más apropiado de moralización (Fernández, 2013). El sistema implantado por Montesinos se dividía en las siguientes fases: 1) la de los hierros, porque el preso estaba sujeta a ella, realizando tareas de limpieza y posteriormente pasaba de manera voluntaria a un taller a aprender un oficio; 2) la del trabajo, por considerarse el mejor medio para reformar al preso; 3) la de la libertad intermedia; se ponía a prueba la rehabilitación porque al recluso se le permitía salir a trabajar por fuera de la cárcel (López, 2012, p. 423).

Con Montesinos también se da inicio a una materia de instrucción. En el presidio de Valencia se impartía enseñanza religiosa y laica, lectura, aritmética, dibujo lineal e instrucción literaria, luego se introdujo la imprenta y se imprimieron numerosas obras de interés educativo. De igual manera, buscó que los reclusos se vieran obligados a reformarse a través del trabajo con responsabilidad, inculcándoles que el delito se queda en la puerta, ejercía una gran vigilancia sobre cada uno de ellos como si fueran sus propios hijos y estos a la vez lo amaban como si fuera su propio padre (Fernández, 2013). Este sistema fue adoptado y recomendado por las Naciones Unidas y paulatinamente se fue implantando en las legislaciones penitenciarias y carcelarias.

El segundo sistema, inglés de Maconochie se implantó en la isla Norfolk (Australia); allí se encontraban los presos que habían vuelto a reincidir después de su excarcelación (Leganés, 2013, p. 28). El capitán de la real marina inglesa, Alexander Maconochie, creó en 1840 el sistema, que consistía en dividir el tiempo de reclusión en los siguientes periodos: 1) periodo de prueba, que consistía en el aislamiento total y en trabajo duro, 2) periodo de trabajo, que se realizaba durante el día, en silencio y en común con sus compañeros, y aislamiento nocturno, y 3) periodo libertad condicional, que se alcanzaba al ganarse una determinada cantidad de vales (Leganés, 2013, pp. 28-29); que eran conocidos en Inglaterra a través de los tickets of leave de Maconochie, el cual se otorgaba a reclusos de buena conducta y trabajo. Se daba como fundamento importante la confianza, para lo 
cual se les sometía a "duras pruebas", que consistían en el empleo de los penados en trabajos como ordenanzas, asistentes, etc., sin mayor vigilancia, y al finalizar el término de la libertad condicional se obtenía la libertad definitiva (Neuman, 1971).

El tercer sistema progresivo Obermayer su promotor George M. Von Obermayer, director de la cárcel Kaiserlantern en Baviera en 1830 y de la cárcel de Munich 1842, se dividía en tres estadios; 1) la vida en común pero en silencio, 2) tras la “observancia de la personalidad”, los reunían con grupos de 25 a 30 compañeros para que vivieran en sociedad y 3) si trabajaba obtenía la libertad condicional con un tercio de antelación (Leganés, 2013, p. 29).

El cuarto sistema de Crofton, cuyo fundador fue Walter Crofton, director de cárceles de Irlanda, comenzó a aplicar en 1854, tras perfeccionar el sistema de Maconochie. Para ello, Walter Crofton creó las prisiones intermedias, en las que se cumplía un periodo intermedio entre la cárcel cerrada y la libertad condicional (Leganés, 2013, pp. 29-30). Este sistema contaba con cuatro periodos: 1) aislamiento celular día y noche; 2) trabajo en común diario en silencio y aislamiento nocturno, 3) se cumplía en cárceles intermedias, esto es, entre la cárcel y la libertad condicional; predominaba el trabajo al aire libre, sobre todo en los campos, 4) libertad condicional; la última etapa de la pena se cumplía en libertad (Leganés, 2013, pp. 29-30).

Esos sistemas son referentes importantes para poder hablar del sistema progresivo que se ha introducido en la mayoría de legislaciones penales hasta nuestros días, desde luego, con modificaciones y para que, a través de sus diferentes etapas, el sentenciado alcance el fin de la pena, que hoy en día es la resocialización. Colombia recogió este sistema, según lo desarrollaremos más adelante.

\section{Sistema de individualización científica}

En España, la historia penitenciaria dividida por Bueno Arús consta de cuatro etapas: 1) 1881 a 1901, indagación de un modelo penitenciario; 2) 1901 a 1936, acomodación del sistema progresivo; 3) 1937 a 1968, consolidación del sistema progresivo; y 4) de 1968 a hoy, adopción de métodos científicos y reconocimiento de derechos humanos del privado de la libertad (Bermejo, 2019, p. 501).

El sistema de individualización científica parte del principio básico de la no existencia de diferencias en los métodos de tratamiento según las fases. El cumplimiento de la condena se diseña de forma individual para cada preso a través de la clasificación penitenciaria, apoyado en las ciencias de la conducta y aplicado 
por especialistas como psicólogos, criminólogos, educadores, etc. En este sistema prevalece "la libre elección de grado en el momento clasificatorio inicial, siendo determinantes, para la progresión o regresión, los criterios que radican en la persona, es decir, los elementos subjetivos" (Bermejo, 2015, p. 129).

El penado al ingresar al centro carcelario es puesto en la fase que su tratamiento penitenciario requiere, la ley reglamenta el plan de cumplimiento individualizado para cada condenado con el tratamiento por aplicar. Ello es operante en Alemania y Suecia, en este país se reglamenta que el tratamiento del interno ha de ser planificado y ejecutado de acuerdo con él (INPEC, 1996).

Este sistema sienta su base en dos fases diferentes y coordinadas entre sí; la primera es una planificación terapéutica y la segunda, una planificación penitenciaria o de ejecución, y sirve para determinar el internamiento en un centro cerrado o abierto, el traslado a una vivienda colectiva o a un grupo de tratamiento, así como el destino laboral o los programas formativos. Se considera que la característica fundamental de este sistema radica en la flexibilidad, que permite que un penado privado de su libertad pueda ser clasificado en cualquier grado, salvo en libertad condicional, sin que ello implique un periodo mínimo de permanencia en dichos grados (Sánchez, 2014).

El sistema de individualización científica lo consagran las Reglas Mandela, específicamente la regla 89, que afirma que se hace necesario

1. El cumplimiento de estos principios exige la individualización del tratamiento, lo que a su vez requiere un sistema flexible de clasificación de los reclusos [...], 3. Es conveniente evitar que en los establecimientos penitenciarios de régimen cerrado el número de reclusos sea tan elevado que llegue a constituir un obstáculo para la individualización del tratamiento. (Reglas Mandela, 2016, pp. 29-36)

\section{Sistema progresivo, tratamiento \\ vs. resocialización en Colombia}

\section{Sistema progresivo en Colombia}

El sistema progresivo se recoge por primera vez en Colombia en el Decreto Ley 1405 de 1934, Código de Régimen Carcelario. Años después, con el Decreto 
Ley 1817 de 1964, se introducen los principios que orientan el sistema progresivo (Leganés, 2013, pp. 955-956). Este Decreto, en su art. 248, consagra, en su primera fase el aislamiento del privado de la libertad, máximo hasta sesenta días sometido a observación para poderlo clasificar en el grupo al que debía pertenecer. Líneas más adelante, en el art. 269 de la misma obra, consagraba que las penas "se cumplen con la obligación del trabajo durante el día y el aislamiento durante la noche, siguiendo las normas del sistema progresivo penitenciario". Mientras que en materia penal sustantiva, el Código Penal de 1936 introduce por primera vez la figura de la libertad condicional como el último eslabón de este sistema progresivo, la cual ha sido reiterativa hasta nuestra actual legislación penal y penitenciaria con algunas modificaciones tanto en el aspecto subjetivo como en el objetivo.

En 1991 se expide la Constitución Nacional, revolucionaria en su momento por la consagración de principios, derechos y garantías. Ello llevó a que los códigos en materia penal se acomodaran a los postulados de la Carta. El primero en dar ese paso fue el actual Código Penitenciario y Carcelario, Ley 65 de 1993, al cual le siguió el Código Penal, Ley 599 de 2000, tomando en su artículo 64 la figura de la libertad condicional, que es la última fase del sistema progresivo.

El art. 12 de la Ley 65 de 1993 acoge el sistema progresivo, superando la etapa del aislamiento que refería la ley derogada, y refiere que "el cumplimiento de la pena se regirá por los principios del sistema progresivo”. Este sistema se toma como un modelo de tratamiento que está dirigido a la promoción del individuo a través de acciones, estrategias, procedimientos, programas y proyectos, y a manera integral y progresiva de acuerdo con los arts. 142 (objetivo del tratamiento), 143 (tratamiento penitenciario) y 144 (fases del tratamiento) de la obra en mención. Igualmente, cabe señalar el art. 22, el cual fue modificado por el art. 3 de la Ley 1709 de 2014, en el que se consagra que la ejecución de la pena de prisión se hará mediante un sistema progresivo para el tratamiento de los internos. Los centros penitenciarios y carcelarios serán categorizados de alta o máxima, media y mínima seguridad.

\section{Tratamiento penitenciario}

Se ha definido como "acción individualizada, tendiente a modificar favorablemente aquel sector de la personalidad del interno que influye, facilitando o provocando, su delincuencia o estado peligroso" (Alarcón, 2016, p. 18). 


\section{La Corte Constitucional lo ha definido como}

[...] el conjunto de mecanismos de construcción grupal e individual, tendientes a influir en la condición de las personas, mediante el aprovechamiento del tiempo de condena como oportunidades, para que puedan construir y llevar a cabo su propio proyecto de vida, de manera tal que logren competencias para integrarse a la comunidad como seres creativos, productivos, autogestionarios, una vez recuperen su libertad. Dando cumplimiento al Objetivo del Tratamiento de preparar al condenado(a) mediante su resocialización para la vida en libertad [...]. (Sentencia T-286, 2011)

El tratamiento penitenciario es adoptado en el Pacto Internacional de Derechos Civiles y Políticos de 1966, numeral 10.3, que dice "el régimen penitenciario consistirá en un tratamiento cuya finalidad esencial será la reforma y la readaptación social de los penados [...]”. Desarrollado en el artículo 10 de la Ley 65 de 1993, el cual regula la finalidad del tratamiento penitenciario, alusivo a que

[...] el tratamiento penitenciario tiene la finalidad de alcanzar la resocialización del infractor de la ley penal, mediante el examen de su personalidad y a través de la disciplina, el trabajo, el estudio, la formación espiritual, la cultura, el deporte y la recreación, bajo un espíritu humano y solidario.

Al respecto, la Corte indicó que "se ha diseñado un complejo sistema técnico de carácter progresivo dividido en varias fases, cada una de las cuales responde al progreso particular que cada interno muestra dentro del proceso de resocialización" (Sentencia T-1670, 2000).

Además, la Corte Constitucional ha sido clara en señalar que lo que compromete es la posibilidad de la resocialización, es la existencia de un sistema que garantice la efectiva reinserción social del individuo, por ello con respecto al tratamiento penitenciario hay que tener en cuenta varios beneficios consagrados en la Ley 65 y que se consideran indispensables:

[...] del cual hacen parte los beneficios administrativos (permisos hasta de 72 horas, libertad y franquicia preparatoria, trabajo extramuros y penitenciaría abierta), y los subrogados penales, que son: la condena de ejecución condicional (art. 68 del C.P.). ... y la libertad condicional (art. 72 del C.P.) [...]. (Sentencia C-329, 2003) 
Así los arts. 142, 143 y 144 de la ley penitenciaria establecen el objetivo, el tratamiento y las fases de este dirigidas a preparar al condenado a la vida en libertad en cumplimiento de la atención social y el tratamiento mediante el programa Plan de Acción y Sistema de Oportunidades (PASO) para alcanzar la resocialización a través del trabajo, estudio, enseñanza, actividad cultural, recreativa, deportiva y relaciones familiares regulados por la Resolución 3190 de 2013. Igualmente, observando las fases exigidas en el art. 144 de la misma ley y reglamentadas por el INPEC, tenemos:

1) Observación, diagnóstico y clasificación del interno en la cual. Se inicia con la difusión de información y la posterior inducción para la población reclusa. Paralelamente se hace un diagnostico individual con información valida y confiable contenida en la cartilla biográfica, de entrevistas con los profesionales y reporte de los funcionarios. Esta valoración permite establecer resultados concretos sobre la personalidad y el proyecto de vida del interno.

2) Alta seguridad que comprende el periodo cerrado. Esta fase está dirigida al tratamiento de condenados, cuyas condiciones de seguridad, circunstancias jurídicas y factores de personalidad medidas precautelativas, que ameritan espacios de tratamiento restrictivos con el ánimo de proteger y prevenir tanto al interno como a la comunidad carcelaria y a la sociedad misma. Las actividades en este proceso se orientan a la intervención terapéutica individual y grupal, la inclusión en programas de educación formal, la capacitación en el desarrollo de habilidades artísticas y artesanales. Y la participación en eventos diversos (culturales, deportivos, recreativos, espirituales, y literarios).

3) Mediana seguridad que comprende el periodo semiabierto. En esta fase se clasifican los internos condenados, cuyo diagnóstico y seguimiento permitan concluir que se pueden desenvolver con medidas menos restrictivas. Las actividades en este proceso se orientan a la intervención especializada se realiza a partir de las recomendaciones sugeridas por los especialistas teniendo en cuenta el desempeño de la fase anterior. El nivel de adherencia al tratamiento. Indicadores de seguimiento, ocupación y rendimiento en los programas ofrecidos.

4) Minima seguridad o periodo abierto. En esta fase acceden los internos condenados, demostrando que ya solo requieren de medidas de baja seguridad y que pueden manejar mayores espacios y responsabilidades para desarrollar su máximo nivel de autocontrol y crecimiento personal. Las actividades en este proceso 
se orientan a valorar los logros y las actitudes. Se califica el desempeño social hacia su familia, comunidad del ERon, calidad de relaciones interpersonales, desarrollo de valores como la tolerancia y la solidaridad, así como el respeto a los límites y normas con responsabilidad.

5) De confianza, que coincidirá con la libertad condicional. En esta fase se representa el último paso por alcanzar en el proceso de tratamiento, debe coincidir con el cumplimiento de las $3 / 5$ partes de la pena. (INPEC, 2020)

Ha dicho la Corte que el carácter progresivo radica en que de forma paulatina se busca reincorporar al recluso a la sociedad, haciendo menos traumático su tránsito a la vida libre (Sentencia T-1670, 2000).

\section{Resocialización}

La resocialización encuentra las bases en los arts. 5, 6, 11.1, 29.2 de la Declaración Universal de los Derechos Humanos, también en el artículo 25 párrafo 3 y artículo 26 párrafo 2 de la Declaración Americana de los Derechos y Deberes del Hombre. Igualmente, en los arts., 5.1, 5.2, 5.6, 7.3, y 8.2 del Pacto de San José de Costa Rica. Y, finalmente, en los arts. 9.3 última parte, 10.1, 10.2a, 10.3, y 14.2 del Pacto Internacional de Derechos Civiles y Políticos (Fleming y Viñals, 1997).

Los arts. 9 y 10 de la Ley 65 de 1993 consagra que el fin de la pena es la "resocialización", la cual se alcanza mediante "el examen de su personalidad y a través de la disciplina, el trabajo, el estudio, la formación espiritual, la cultura, el deporte y la recreación, bajo un espíritu humano y solidario”.

El término "resocialización" como lo menciona Emiro Sandoval se puede usar indiscriminadamente, también como reinserción social, readaptación social, reeducación social, rehabilitación social, etc. (Sandoval, 1998). La resocialización en el contexto penitenciario parte de dos criterios:

i) que mediante una serie de prácticas especializadas se logre el cambio de la persona condenada y, ii) que a través de las practicas durante la privación de la libertad es posible obtener resultados. El tratamiento penitenciario para lograr los fines resocializadores de la pena debe tener efectos preventivos sobre la reincidencia para que no sean nuevamente condenados. (Sentencia T-153, 1998) ${ }^{1}$

1 Lineamientos para el fortalecimiento de la política penitenciaria en Colombia. "La labor de resocialización no consiste en imponer determinados valores a los reclusos, sino en brindarles los 
La Corte ha hecho ver la importancia de la resocialización al afirmar que

[...] durante la ejecución de las penas debe predominar la búsqueda de resocialización del delincuente, ya que esto es una consecuencia natural de la definición de Colombia como un Estado social de derecho fundado en la dignidad humana, puesto que el objeto del derecho penal en un Estado de este tipo no es excluir al delincuente del pacto social sino buscar su reinserción en el mismo. (Sentencias C-261 y C-656 de 1996) $)^{2}$

Luego el tratamiento penitenciario es indispensable para alcanzar la resocialización, por ello los establecimientos penitenciarios y carcelarios "tienen el deber de restaurar los lazos sociales de los reclusos con el mundo exterior, pues de ello dependerá, en gran parte, la posibilidad de resocialización” (Sentencia T-213, 2011). Así, la función de la pena está orienta a la preparación del sentenciado para su retorno a la sociedad (Ministerio de Justicia, 2016) y la idea de resocialización se opone a penas y condiciones de cumplimiento que por su duración y sus consecuencias sean desocializadoras (Sentencia C-656, 1996).

\section{Ineficacia del sistema progresivo en Colombia}

Como se dijo en un acápite anterior, la Ley 65 de 1993 tomó el sistema progresivo penitenciario. Para acceder, el condenado al tratamiento estableció cinco fases, recordémoslas para verificar su cumplimiento. El art. 144 de la ley en cita, las clasifica en fases: 1) observación, diagnóstico y clasificación del interno; 2) alta seguridad que comprende el período cerrado; 3) mediana seguridad que comprende el período semiabierto; 4) mínima seguridad o período abierto; y 5) de confianza, que coincidirá con la libertad condicional (Niño, 2016).

medios para que, haciendo uso de su autodeterminación, establezca cada interno el camino de su reinserción al conglomerado social” (pp. 20-21).

2 De igual manera, la Corte ha resaltado que "las cárceles no constituyen únicamente lugares de castigo o de expiación de los delitos, sino que, desde el punto de vista del interés social, cumplen la función de rehabilitar y readaptar al delincuente, constituyéndose a la vez en factores esenciales de la seguridad y la paz colectivas, pues la reclusión de enemigos públicos, aunque no implique la eliminación total ni definitiva de los riesgos que afronta el conglomerado social — siempre asediado por la delincuencia - contribuye significativamente a su disminución" (Corte Constitucional, Sentencia T-065, 1995). 
El art. $145^{3}$ de la Ley 65 de 1993 establece el Consejo de Evaluación y Tratamiento. Modificado por el art. 87, Ley 1709 de 2014, refiere:

Este consejo determinará los condenados que requieran tratamiento penitenciario después de la primera fase. Dicho tratamiento se regirá por las guías científicas expedidas por el INPEC y por las determinaciones adoptadas en cada consejo de evaluación. En caso de no ser necesario el tratamiento penitenciario, el Instituto Nacional Penitenciario y Carcelario reglamentará el cumplimiento de las fases restantes.

Frente a la primera fase, la Corte mencionó que "la clasificación brinda condiciones de seguridad - incluso para los mismos reclusos—, elemento esencial del orden público, que constituye un derecho de la sociedad y un deber del Estado" (Sentencia n. ${ }^{\circ}$ C-394, de 1995). La segunda fase es la de alta seguridad de periodo cerrado que debe cumplir en el establecimiento penitenciario o carcelario designado mediante Resolución por el INPEC.

Analicemos las fases restantes a partir de referentes doctrinales. La tercera fase, que es el período semiabierto, dice Del Pont que consiste en autorizar al interno a trabajar fuera del establecimiento, en condiciones similares a la vida libre, regresando luego a él (Del Pont, 1975, p. 31), situación que no se compadece con lo referenciado en Colombia, porque en esta fase se limita a realizar un "seguimiento que permitan concluir que se pueden desenvolver con medidas menos restrictivas", mas no se le autoriza que pueda salir a laborar, estudiar o enseñar por fuera del penal. En el cuarta fase, "mínima seguridad o período abierto", un concepto desde la doctrina es que se caracteriza por la ausencia de obstáculos físicos, esto es, fundamentado en la confianza, dando lugar a una verdadera extensión del régimen abierto y la forma ideal de la ejecución abierta sería la comunidad de vida con un alto grado de autorregulación (De la Cuesta, 1996, p. 66). Mientras que el INPEC reconoce esta fase como aquella en la "acceden los internos condenados, demostrando que ya solo requieren de medidas de baja seguridad y que pueden manejar mayores espacios y responsabilidades para desarrollar su máximo nivel de

3 En la primera parte del artículo establece quiénes conforman los grupos interdisciplinarios en los centros penitenciarios y carcelarios del país. "E1 tratamiento del sistema progresivo será realizado por medio de grupos interdisciplinarios integrados por abogados, psiquiatras, psicólogos, pedagogos, trabajadores sociales, médicos, terapistas, antropólogos, sociólogos, criminólogos, penitenciaristas y miembros del cuerpo de custodia y vigilancia” (Ley 65 de 1993). 
autocontrol y crecimiento personal"; la Corte, por su parte, al hablar de esta fase la definió como:

El período de mínima seguridad, denominado también abierto, y hace relación a ciertos beneficios que se conceden a quienes ya han cumplido las cuatro quintas partes del tiempo requerido para obtener la libertad condicional, sin que se pueda entender que dentro de los beneficios legales concedidos se encuentre la obligatoriedad de mantener las celdas abiertas durante todo el día por parte de las autoridades administrativas. (Sentencia T-895, 2013)

En la quinta y última fase (la de confianza), se indica que se accede a ella previo cumplimiento del factor subjetivo y con el tiempo requerido para la libertad condicional como factor objetivo. Esta termina con el cumplimiento de la pena. En esta fase el proceso se orienta al desarrollo de actividades que permitan evidenciar el impacto del tratamiento. En esta fase se clasificará aquellos internos que: 1) hayan superado el tiempo requerido para la libertad condicional; 2) hayan demostrado un efectivo y positivo cumplimiento del tratamiento penitenciario; y 3) cuenten, previa verificación desde el ámbito externo a la prisión, con apoyo para fortalecer aún más su desarrollo integral (Sentencia T-895, 2013).

Consideramos que lo plasmado en la ley sobre las fases 3 y 4 es contradictorio con la interpretación que a nivel de doctrina se le da, con respecto a los términos allí utilizados "semi libertad y abierto", porque el privado de la libertad continúa en un medio cerrado hasta alcanzar su libertad condicional; en muchos casos, cumple la pena en un solo centro carcelario y el cambio de una fase a otra solo se da en el papel (Gamboa, 2016).

\section{Validez del tratamiento penitenciario}

Se surte por las diferentes actividades (trabajo, estudio y enseñanza) consagradas en la Ley 65 de 1993, que cumplen la función de redimir pena y de resocializar al privado de la libertad, como se mencionó en párrafos anteriores.

Eficacia de la redención por trabajo, estudio y enseñanza

El art. 10 de la Ley 65 de 1993 consagra que el tratamiento penitenciario tiene la finalidad de alcanzar la resocialización del infractor de la ley penal, como también 
sirve de redención de pena (Sentencia T-266, 2013) en atención a lo establecido en los arts. 824, 975, 986. Y, por último, la Ley 1709 de 2014 consagró la redención como un derecho y no un beneficio de los condenados (Sentencia T-718, 2015). Además, la Corte aclaró que la figura de redención de pena es la materialización de la función resocializadora de la pena (sentencias T-718, 2015 y T-100, 2018).

Un análisis a los datos reportados por el INPEC puede mostrar los cambios presentados antes y después de la expedición de la Ley 1709.

Tabla 1. Informe estadístico, marzo 2020

\begin{tabular}{|c|c|c|c|c|c|}
\hline Año & Población condenada & Trabajo & Estudio & enseñanza & Total \\
\hline 2013 & 81792 & 38108 & 41649 & 1516 & 81273 \\
\hline 2014 & 77634 & 42078 & 44669 & 1700 & 88447 \\
\hline 2017 & 77973 & 45566 & 45147 & 1711 & 92424 \\
\hline 2018 & 78464 & 45888 & 47163 & 1851 & 94902 \\
\hline 2019 & 81123 & 47105 & 47884 & 1842 & 96831 \\
\hline 2020 & 80050 & 49147 & 50818 & 1925 & 101890 \\
\hline
\end{tabular}

Fuente: Revista de entre muros para la libertad, ediciones 2013, 2014, 2015, 2016 y 2017, e Informe Estadístico, diciembre de 2018 y 2019 (marzo de 2020). INPEC.

Se puede observar, con respecto a la redención, que en el año 2013 los cupos disponibles en trabajo, estudio y enseñanza son mínimos frente a la población condenada y se desprende que 519 sentenciados no pueden acceder al tratamiento penitenciario. En 2014, en vigencia de la Ley 1709, el fenómeno cambia y comienzan a sobrar cupos, como se observa en la tabla 1 , lo que implica que la población imputada y procesada está teniendo acceso a tratamiento. Luego el cambio dado

$4 \quad$ Establece los parámetros a tener en cuenta para el recluso que desarrolla alguna actividad de las reglamentadas por el INPEC, mientras permanece en privación de la libertad. "A los detenidos y a los condenados se les abonará un día de reclusión por dos días de trabajo. Para estos efectos no se podrán computar más de ocho horas diarias de trabajo” (Ley 65 de 1993).

5 Parámetros para los privados de la libertad que estudian. "A los detenidos y a los condenados se les abonará un día de reclusión por dos días de estudio. Se computará como un día de estudio la dedicación a esta actividad durante seis horas, así sea en días diferentes” (Ley 65 de 1993).

6 Parámetros para los privados de la libertad que cuentan con las capacidades educativas para ser instructor y enseñar. "El recluso que acredite haber actuado como instructor de otros, en cursos de alfabetización o de enseñanza primaria, secundaria, artesanal, técnica y de educación superior tendrá derecho a que cada cuatro horas de enseñanza se le computen como un día de estudio, siempre y cuando haya acreditado las calidades necesarias de instructor o de educador, conforme al reglamento" (Ley 65 de 1993). 
por la mencionada ley, en el entendido de que la redención de pena sea un derecho y no un beneficio, fue un avance en el sistema progresivo, dado que el $100 \%$ de los condenados realizan alguna actividad y con ello algunos alcanzan el subrogado penal de la libertad condicional, amparados en que han alcanzado la resocialización, como en igual forma a los que están cumpliendo la totalidad de la pena, por habérseles negado en su momento el subrogado aludido (Ballesteros, 2015).

\section{Ineficacia de la resocialización}

La Corte determinó que uno de los fines constitucionales de la pena es la resocialización (Sentencia C-261, 1966) dentro del respeto por la autonomía y dignidad; y no es excluirlo de la comunidad política, sino, como lo ha mencionado en repetidas oportunidades la Corte, es buscar su reinserción. Además, aclaró que

[...] el proceso de resocialización está edificado sobre un conjunto de factores que deben concurrir para garantizar las condiciones necesarias para su eficacia: (i) la oportunidad y disposición permanente de medios que garanticen la realización de diversas actividades de orden laboral, educativo, deportivo y lúdico; (ii) las condiciones cualificadas de reclusión, en aspectos básicos como el goce permanente de servicios públicos esenciales, buenas condiciones de alojamiento, alimentación balanceada, servicios sanitarios mínimos, etc. y (iii) el acompañamiento permanente durante el periodo en que se prolonga la privación de la libertad, con el auxilio de un equipo interdisciplinario de profesionales en ciencias sociales y de la salud, de la red de apoyo y de la familia del recluso. (Sentencia T-1190 de 2003)

Teniendo claro los fines y factores que deben concurrir para la resocialización, la Corte encontró que el régimen carcelario no dispone de parámetros claros sobre los programas de resocialización, que hay desarticulación de la formulación de estos y no hay un proceso de seguimiento que permita reestructurar estrategias en busca de la disminución de la criminalidad (Sentencia T762 de 2015). Estos aspectos, aunados al hacinamiento carcelario, llevan a que sean antecedentes claros de la no existencia de la resocialización (Valderrama, Téllez y Blanco, 2018).

Si bien es cierto que hay condenados que no regresan a las actividades delictivas, también es verdad que un porcentaje regresa a la delincuencia y otro porcentaje se queda en los centros carcelarios cumpliendo la totalidad de la pena precisamente por 
no alcanzar su resocialización. Analicemos el fenómeno sucintamente de acuerdo con los datos aportados por el INPEC, según se muestra en la tabla 2.

Tabla 2. Reincidencia del 2010 a 2019

\begin{tabular}{|c|c|c|}
\hline Año & Condenados & Reincidentes \\
\hline 2012 & 77572 & 14777 \\
\hline 2013 & 79353 & 16903 \\
\hline 2014 & 82868 & 11783 \\
\hline 2015 & 75627 & 13415 \\
\hline 2016 & 77393 & 14737 \\
\hline 2017 & 80569 & 15311 \\
\hline 2018 & 78458 & 16079 \\
\hline 2019 & 79254 & 18425 \\
\hline
\end{tabular}

Fuente: elaboración del autor con base Entre muros para la libertad, revista del INPEC.

La cifra de reincidentes es alta frente a la población condenada, y en lugar de disminuir sucede lo contrario, es decir, aumenta en más de mil, de manera que frente a ellos no opera la resocialización.

Ahora, analicemos a los privados de la libertad que están cumpliendo la totalidad de la pena por no alcanzar igualmente la resocialización y no beneficiarse de subrogado alguno, para el caso la libertad condicional (tabla 3).

Tabla 3. Solicitudes y otorgamiento de libertad por pena cumplida

\begin{tabular}{|c|c|c|c|c|}
\hline Año & Solicitud & Otorgadas & No concedidas & En trámite \\
\hline 2014 & 5158 & 4791 & No establece & No registra \\
\hline 2015 & 5508 & 4281 & No establece & No registra \\
\hline 2016 & 5979 & 5138 & No establece & 841 \\
\hline
\end{tabular}

Fuente: elaboración propia con base en información del INPEC.

Causa curiosidad las cifras que reporta el InPEC de los años 2014 al 2016 en las revistas entre muros para la libertad de las personas en dicha condición, esto es, que el juez de ejecución de penas y medidas de seguridad en su momento consideró que no se resocializaron y como consecuencia deben pagar la totalidad de la pena de prisión impuesta. Es bastante preocupante porque es bien sabido que 
en los centros penitenciarios y carcelarios no es factible la resocialización que está precisamente en cabeza del Estado.

Así, compartimos el reconocimiento que ha hecho la Corte Constitucional de la no resocialización de los sentenciados:

[...] las condiciones de hacinamiento impiden brindarles a todos los reclusos los medios diseñados para el proyecto de resocialización, estudio, trabajo, etc. Dada la imprevisión y el desgreño que han reinado en materia de infraestructura carcelaria, la sobrepoblación ha conducido a que los reclusos ni siquiera puedan gozar de las más mínimas condiciones para llevar una vida digna en la prisión, tales como contar con un camarote, agua suficiente, servicios sanitarios, asistencia en salud, visitas familiares en condiciones decorosas, etc. (Sentencia T-153, 1998)

Lo ratificó en sus sentencias T-388 de 2013 y T-762 de 2015. Igualmente, adujo que "el sistema penitenciario y carcelario actual es incompatible con un estado social y democrático de derecho" (Sentencia T-388 de 2013).

\section{Conclusiones}

La pena de prisión, a través del sistema progresivo consagrado en la ley, tiene un fin primordial, que es la resocialización del sentenciado, la cual se alcanza mediante el tratamiento penitenciario, focalizado en que el privado de la libertad trabaje, estudie o enseñe, conductas que igualmente le sirven para redimir la pena. No obstante, esta es inoperante y a la vez un fracaso, toda vez que dentro de los establecimientos carcelarios y penitenciarios de Colombia no se cuenta con los recursos materiales ni humanos para garantizar el acceso a los mecanismos para la resocialización. Adicionalmente, las condiciones indignas en las cuales viven las personas privadas de la libertad por el permanente hacinamiento llevan a cuestionar la existencia de intenciones reales para su resocialización. En este sentido, la Comisión Interamericana de Derechos Humanos informó que el sistema carcelario en Colombia está superado por la superpoblación carcelaria. Además, se ha mostrado incapaz de separar procesados de condenados, de crear condiciones de seguridad mínima para evitar la criminalidad interna a los propios establecimientos, y de diseñar y ejecutar programas efectivos de rehabilitación. Contribuyen a esta situación la rigidez de la legislación penal, la lentitud judicial y la falta de utilización de medidas preventivas 
diferentes a la prisión y de las alternativas para el cumplimiento de las sentencias (сіDH, Cap. 14, num. 62).

Al estar demostrado que la resocialización es el fin de la pena y que su fundamento procede del tratamiento que recibe el privado de la libertad en las diferentes fases del sistema progresivo, consideramos que este se debe evaluar, replantear y conceptualizar, para poder llevarlo al plano de la realidad, en el que el privado de la libertad pueda percibir el cambio que implica estar en una fase y beneficiarse de la siguiente en aras de alcanzar su libertad. Este sistema progresivo en sus diferentes fases es viable, lo que lo hace un fracaso es cuando se lleva al plano de la realidad.

El incumplimiento de derechos universales como la dignidad humana y la concepción punitivista de la sociedad colombiana no solamente nos llevan a proponer el acatamiento del sistema progresivo y la generación de políticas públicas basadas en la equidad y la justicia social, para sí poder tener en Colombia un sistema que responda con las finalidades consagradas hoy en el derecho penitenciario del país y con la garantía de la dignidad, inherente a todo ser humano.

\section{Referencias}

Alarcon, B. J. (2016). El tratamiento penitenciario. Recuperado de http://www.cienciaspenales.net/files/2016/11/3_tratamiento-penitenciario.pdf

Anitua, G. I. (2004). "Contradicciones y dificultades de las teorías del castigo en el pensamiento de la Ilustración”. En I. Rivera Beiras (Coord.), Mitologías y discursos sobre el castigo (pp. 13-32). España: Ánthropos.

Ballesteros, C. (2015). La mujer y el ejercicio efectivo del poder en Colombia, una cuestión de Derechos Humanos. Revista Verba Iuris, 33, 61-76. Recuperado el 8 de mayo de 2018 de https://revistas.unilibre.edu.co/index.php/verbaiuris/article/view/27/24

Beccaria, C. (2015). Tratado de los delitos y de las penas. Madrid, España. Universidad Carlos III. Recuperado de http://hdl.handle.net/10016/20199.

Bermejo, D. F. (2019). Del sistema progresivo a la individualización científica. La elaboración de la Ley General Penitenciaria y la relevancia del bienio 1978-1979 en el derecho penitenciario. Anuario de Derecho Penal y Ciencias Penales, 72(1), 483-519.

Bueno Arús, F. (1981). Cien años de legislación penitenciaria (1881-1981). Revista de Estudios Penitenciarios, 232-235, 63-84. 
Congreso de la República. (20 de enero de 2014). Ley 1709 de 2014. Por medio de la cual se reforman algunos artículos de la Ley 65 de 1993, de la Ley 599 de 2000, de la Ley 55 de 1985 y se dictan otras disposiciones.

Código Penal Colombiano (CPC). Ley 599 de 2000. Julio 24 de 2000 (Colombia).

Código Penitenciario y Carcelario. (CPC). Ley 65 de 1993. Agosto 19 de 1993 (Colombia).

Decreto Ley 1405 de 1934 Código de Régimen Carcelario. Julio 7 de 1934.

Decreto Ley 1817 de 1964. Por el cual se reforma y adiciona el Decreto-ley 1405 de 1934 (Código Carcelario), y se dictan otras disposiciones.

Corte Constitucional de Colombia (7 de septiembre de 1995). Sentencia n. ${ }^{\circ}$ C-394, M.P. Vladimiro Naranjo Mesa.

Corte Constitucional de Colombia (21 de febrero de 1995). Sentencia T 065 de 1995, [M. P. Alejandro Martínez Caballero].

Corte Constitucional de Colombia (13 de junio de 1996). Sentencia C-261. [M. P. Alejandro Martínez Caballero].

Corte Constitucional de Colombia. Sentencia C-656 de 1996 [M. P. Alejandro Martínez Caballero].

Corte Constitucional de Colombia. (19 de marzo de 1997). Sentencia C-144. [M. P. Alejandro Martínez Caballero].

Corte Constitucional de Colombia. (28 de abril de 1998). Sentencia T-153. [M. P. Eduardo Cifuentes Muñoz].

Corte Constitucional de Colombia. (5 de diciembre de 2000). Sentencia T-1670 [M.P. Carlos Gaviria Díaz].

Corte Constitucional de Colombia. (29 de abril de 2003). Sentencia C-329. [M. P. Álvaro Tafur Galvis].

Corte Constitucional de Colombia. (4 de diciembre de 2003). Sentencia T-1190.

[M. P. Eduardo Montealegre Lynett].

Corte Constitucional de Colombia. (27 de marzo de 2011). Sentencia T-213. [M. P. Gabriel Eduardo Mendoza Martelo].

Corte Constitucional de Colombia. (14 de abril de 2011). Sentencia T-286. [M. P. Jorge Ignacio Pretelt Chaljub]. 
Corte Constitucional de Colombia. (8 de mayo de 2013). Sentencia T-266. [M. P. Jorge Iván Palacio Palacio].

Corte Constitucional de Colombia. (3 de diciembre de 2013). Sentencia T-895. [M. P. Jorge Iván Palacio Palacio].

Corte Constitucional de Colombia. (28 de junio de 2013). Sentencia T-388 [M. P. María Victoria Calle Correa].

Corte Constitucional de Colombia. (16 de diciembre de 2015). Sentencia T762. [M. P. Gloria Stella Ortiz Delgado].

Corte Constitucional de Colombia. (24 de noviembre de 2015). Sentencia T-718. [M. P. Jorge Iván Palacio Palacio].

Corte Constitucional de Colombia. (22 de junio de 2016). Sentencia C-328. [M. P. Gloria Stella Ortiz Delgado].

Corte Constitucional de Colombia. (22 de marzo de 2018). Sentencia T-100. [M. P. Gloria Stella Ortiz Delgado].

Corte Interamericana de los Derechos Humanos. (CIDH) (1999). Los derechos de las personas privadas de su libertad. Capítulo 14, numeral 62. Recuperado de http://www.cidh.org/ countryrep/colom 99sp/capitulo-14.htm.

De la Cuesta, A. J. L. (1996). El régimen abierto. Anuario de derecho penal y ciencias penales, 49(1), 59-92.

De Lardizabal, M. (1782). Discurso sobre las penas contrabido a las leyes criminales de España, para facilitar su reforma. Madrid, España: Joachin Ibarra.

Del Pont, L. M. (1975). Penología y sistemas carcelarios. Tomo I. Buenos Aires, Argentina: Ediciones Depalma.

Del Pont, L. M. (1982). Penología y Sistemas Carcelarios. Tomo II. Buenos Aires, Argentina: Depalma.

Deym, J. (2011). Crisis de la pena privativa de la libertad. Buenos Aires, Argentina: Universidad Argentina Jhon F Kennedy.

E1 Espectador. (14 de mayo de 2019). Encerrar y botar la llave. Judicial. Recuperado https:/ ww.elespectador.com/noticias/judicial/las-carceles-colombianas-el-fracaso-delas-politicas-del-garrote-articulo-860509 
Fernández, B. D. (2013). Individualización científica y tratamiento en prisión. España. Colección: Premio Nacional Victoria Kent. Edita: Ministerio del Interior - Secretaría General Técnica.

Fernández, B. D. (2015). El sistema de ejecución de condenas en España: el sistema de individualización científica. Estudios Penales y Criminológicos, XXXV, 125-187. ISSN 1137-7550.

Fernández, C. (2005). Introducción al sistema penitenciario español. Depósito Legal S.E -479-03. España: Edición noviembre de 2005,

Fleming, A. y Viñals, P. (2014). Las penas. Prólogo de José Daniel Cesano. Buenos Aires, Argentina: Rubinzal-Culzoni Editores.

Foucault, M. (2002). Vigilar y castigar. Nacimiento de la prisión. Buenos Aires, Argentina: Siglo XXI. Recuperado de https://sociologia1unpsjb.files.wordpress.com/2008/03/ foucault-vigilar-y-castigar.pdf

Gamboa, S. (2016) A propósito de una verdad contrahegemónica: aprendizajes desde la decisión de la Corte Penal Internacional sobre el ataque contra la flotilla de la libertad. Revista Via Inveniendi et Iudicandi, 11(1), 11-35. Recuperado el 5 de mayo de 2018 de http://revistas.usantotomas.edu.co/index.php/viei/article/view/2925/2797

Hernández, G. A. (2008). El tratamiento penitenciario, una mirada desde la criminología. Convenio Interinstitucional entre la Universidad Nacional de Colombia y el Instituto Nacional Penitenciario y Carcelario, inPEC n. ${ }^{\circ} 29$. Recuperado de http://extension. upbbga.edu.co/inpec2009/Estudiosprimeraparte/areasdisciplinares/criminologIa.pdf octubre de 2015.

Howard, J. (2004). El estado de las prisiones en Inglaterra y Gales. Estudio Introductorio de Sergio García Ramírez. México: Fondo de Cultura Económica. [Trad. de José Esteban Calderón].

Instituto Nacional Penitenciario y Carcelario (INPEC). (1996). Sistema progresivo penitenciario. Sanfe de Bogotá, Colombia. Recuperado de http://www.inpec.gov.co/portal/ page/portal/Inpec/Institucion/Estudios\%20Penitenciarios/1.3.pdf.

Instituto Nacional Penitenciario y Carcelario (INPEC). (23 de octubre de 2013). Resolución 3190. Recuperado de http://epn.gov.co/elearning/distinguidos/TRATAMIENTO/1_ resolucin_3190_del_23102013.html, p. 3. 
Instituto Nacional Penitenciario y Carcelario (INPEC). (2015). Revista de entre muros para la libertad, 3. Recuperado el 20 de mayo de 2017 de http://www.inpec.gov.co/portal/ page/porta1/Inpec/Institucion/Estad\%EDsticas/Estadisticas/Informes\%20y\%20Boletines\%20Estad\%EDsticos/DE\%20ENTRE\%20MUROS\%20PARA\%20LA\%20 LIBERTAD\%202015.pdf.

Instituto Nacional Penitenciario y Carcelario (INPEC). (2018). Informe estadístico enero de 2018. [En línea], 15 de marzo de 2017. Disponible en http://www.inpec.gov.co/portal/ page/portal/Inpec/Institucion/Estad\%EDsticas/Estadisticas/Informes\%20y\%20Boletines\%20Estad\%EDsticos/1\%20INFORME\%20ENERO\%202018.pdf.

Instituto Nacional Penitenciario y Carcelario (INPEC). (2018). Informe reincidencia del 2010 al 2017. [En linea] 15 de marzo 2019. Disponible en https://www.inpec. gov.colestadisticas/ informes-y-boletines/-/document_library/6SjHVBGriPOM/view_file/632488?_com_liferay_document_library_web_portlet_DLPortlet_INSTANCE_6SjHVBGriPOM_version $=1.0$

Instituto Nacional Penitenciario y Carcelario (INPEC). (2020). "Fases del tratamiento penitenciario de acuerdo a los lineamientos del sistema progresivo". Recuperado de http://epn. gov.co/elearning/distinguidos/TRATAMIENTO/32_fases_del_tratamiento_penitenciario_de_acuerdo_a_los_lineamientos_del_sistema_progresivo.html

Leganés, G. S. (2013). Clasificación penitenciaria y medio abierto. Tomo II. (Tesis doctoral). Ministerio del Interior. Bogotá D. C., Colombia.

López, M. M. (2015). Los derechos fundamentales civiles y sociales de los internos en centros penitenciarios y su libertad (pp. 169-200). Anuario Facultad de Derecho. Universidad de Alcalá. Issn 1888-3214, 9 161. Recuperado de http://dspace.uah.es/dspace/bitstream/ handle/10017/24218/derechos_lopez_AFDUA_2015.pdf

López Melero, M. (2012). Evolución de los sistemas penitenciarios y de la ejecución penal. Anuario de la Facultad de Derecho, 5, 401-448. Universidad de Alcalá, España.

Ministerio de Justicia de Colombia (2016). Lineamientos para el fortalecimiento de la política penitenciaria en Colombia. Dirección de Política Criminal y Penitenciaria Proyecto Fortalecimiento y Seguimiento a la Política Penitenciaria en Colombia. Recuperado de https:/www.minjusticia.gov.co/Portals/0/sala\%20de\%20prensa/documentos/ Lineamientos\%20sistema\%20penitenciario\%20\%20Consulta\%20W.

Molina González, Y. (2016). Derecho penal del enemigo y dignidad humana. Revista Verba Iuris, 11(36), 135-146. 
Muñoz Conde, F. y García, A.M. (2010). Derecho penal. Parte general. Valencia, España: Tirant lo Blanch. Recuperado de https://www.derechopenalenlared.com/libros/Derecho_Penal_Parte_General_Munoz_Conde_Mercedes_Aran.pdf

Naciones Unidas. Comité de Derechos Humanos. (1999). Informe sobre violaciones de los derechos humanos de las personas detenidas en Colombia. Sexto Informe de Colombia. Presentado por Grupo de Derecho de Interés Público. Facultad de Derecho. Universidad de los Andes. Bogotá: Colombia-Ginebra, Suiza. Recuperado de https://tbinternet.ohchr.org/Treaties/ CCPR/Shared\%20Documents/COL/INT_CCPR_NGO_COL_99_8442_S.pdf

Naciones Unidas. Pacto Internacional de Derechos Civiles y Políticos. Adoptado y abierto a la firma, ratificación y adhesión por la Asamblea General en su resolución 2200 A (XXI), de 16 de diciembre de 1966.

Naciones Unidas. Declaración Universal de Derechos Humanos. Adoptada y proclamada por la Asamblea General en su Resolución 217 A (III), de 10 de diciembre de 1948.

Naciones Unidas. (2015). Reglas Minimas de las Naciones Unidas para el Tratamiento de los Reclusos (Reglas Nelson Mandela, 2016). Adoptadas en el Primer Congreso de las Naciones Unidas sobre Prevención del Delito y Tratamiento del Delincuente en 1955 y aprobadas por el Consejo Económico y Social en sus resoluciones $663 \mathrm{C}$ (XXIV), de 31 de julio de 1957, y 2076 (LXII), de 13 de mayo de 1977.

Naciones Unidas. Asamblea General (2016). Resolución aprobada por la Asamblea General el 17 de diciembre de 2015. Sobre la base del informe de la Tercera Comisión. Reglas Mínimas de las Naciones Unidas para el Tratamiento de los Reclusos. Recuperado de http://www.acnur.org/t3/fileadmin/Documentos/BDL/2016/10266.pdf?view=1

Naciones Unidas (1990). Principios básicos para el tratamiento de los reclusos. Adoptados y proclamados por la Asamblea General de las Naciones Unidas en su Resolución 45/111, de 14 de diciembre de 1990. Recuperado de https://www.ohchr.org/SP/ProfessionaIInterest/Pages/BasicPrinciplesTreatmentOfPrisoners.aspx

Neuman, E. (1971). Evolución de la pena privativa de la libertad y regímenes penitenciarios. Buenos Aires, Argentina: Pannedille.

Niño, C. (2016). Exportación de conocimiento: Colombia como proveedor de seguridad para la lucha contra el terrorismo y el crimen internacional en Revista Via Inveniendi et Iudicandi, 11(2), pp. 34-56. 
Rodríguez, A. J. (2013). El ordenamiento jurídico penitenciario español vigente: Carencias y disfunciones. Tesis doctoral. Universidad de Granada, Granada, España. Recuperado el 20 de diciembre 2019. https://digibug.ugr.es/handle/10481/30844

Rojas, H. F. (1977). Criminalidad y constituyente: elementos para un análisis del crimen en las sociedades capitalistas. Bogotá D. C., Colombia: Cinep.Rusche, G. y Kirchheimer, O. (1984). Pena y estructura social. Bogotá D. C., Colombia: Temis.

Quintero, S. y Molina, D. (2013). La ilegalidad: una herramienta de análisis para la naturaleza del conflicto en Colombia. Revista Via Inveniendi et Iudicandi, 8(1), 1-23. Recuperado el 6 de marzo de 2018 de http://revistas.usantotomas.edu.co/index.php/ viei/article/view/846/1127

Saldoval, H. E. (1998). Penología parte general y especial. Bogotá D. C., Colombia: Ediciones Jurídicas Gustavo Ibáñez.

Sánchez, S. C. (2014). La clasificación inicial en tercer grado de tratamiento penitenciario: Desde su contexto legal a su aplicación práctica. (Tesis doctoral). Universidad de Murcia. Facultad de Derecho. Recuperado el 20 de agosto de 2014 http://hdl.handle. net/10201/29642.

Steffen, C. A. (1971). Prisión abierta. Santiago de Chile, Chile: Editor Jurídico de Chile.

Programa Nacional de Ciencias Sociales y Humanas, Colciencias. (2014). El informe final de sistema progresivo penitenciario alternativo como modelo de intervención para el sistema carcelario y penitenciario en Colombia, pp. 22-24. Recuperado www.asamblea. go.cr/Defensoria_de_los_Habitantes/Informe\%202009.2010/Informe\%20Anual\%20 de\%20Labores\%202009-2010.pd\}f.

Tocora, L. F. (2013). Cárceles. Laberintos y cerrojos. Nuevo Foro Penal, 9(80), 135-162. Recuperado de http://publicaciones.eafit.edu.co/index.php/nuevo-foro-penal/article/ view/2256/2186

Valderrama, I. Téllez, R. y Blanco, C. (2018). "La incertidumbre de las víctimas dentro del Acuerdo para la Construcción de una Paz Estable y Duradera”. Editor: Ediciones USTA. En Tendencias actuales de los Derechos Humanos y el Derecho Internacional Humanitario en Colombia (pp. 83-103). Recuperado el 3 de febrero de 2019 de https://repository.usta. edu.co/handle/11634/13049 